\title{
Optimum dose of ginger root oil to treat sterile Mediterranean fruit fly males (Diptera: Tephritidae)
}

B. J. Paranhos ${ }^{1}$, D. McInnis ${ }^{2}$, R. Morelli ${ }^{3}$, R. M. Castro ${ }^{1}$, L. Garziera ${ }^{1}$, L. G. Paranhos ${ }^{1}$, K. Costa $^{4}$, C. Gava ${ }^{1}$, M. L. Z. $\operatorname{Costa}^{4}$ \& J. M. M. Walder

1 Laboratory of Entomology, Embrapa Semi Arid, Petrolina-PE, Brazil

2 USDA-ARS Pacific Basin Agricultural Research Center, Honolulu, HI, USA

3 Department of Entomology and Acarology - USP/ESALQ, Piracicaba-SP, Brazil

4 Laboratory of Food Irradiation and Radio-Entomology, CENA - University of São Paulo, Piracicaba-SP, Brazil

\section{Keywords}

Ceratitis capitata, aromatherapy, medfly,

sterile insect technique

\section{Correspondence}

Beatriz Jordão Paranhos (corresponding author), Embrapa Semiárido, BR 428, km 152, C.P. 23, 56.302-970, Petrolina-PE, Brazil.

E-mail: bjordao@cpatsa.embrapa.br

Received: April 22, 2010; accepted: October 30, 2010.

doi: $10.1111 / j .1439-0418.2010 .01595 . x$

\begin{abstract}
The sterile insect technique (SIT) is widely used as part of an integrated approach to reduce field populations of the Mediterranean fruit fly (Ceratitis capitata, Diptera: Tephritidae). Aromatherapy based on exposure to ginger root oil (GRO) volatiles is known as a method to significantly improve the sexual performance of sterile medfly males, and is being used in many mass-rearing facilities around the world. However, the optimum dose of GRO is not well defined. This work evaluated in laboratory cages four different doses of GRO and a control $(0,0.1,0.25,0.5$ and $0.75 \mathrm{ml} / \mathrm{m}^{3}$ ), and two different methods to hold flies prior to release (paper bags and plastic cages). The objective was to find the lowest dose that provides optimal improvement in mating performance of sterile males when competing with wild males for wild females and optimal reduction in fertility of wild females. Egg hatch, copula duration, the Relative Sterility Index (RSI), and a Competitiveness (C) value (based on RSI) were calculated for each treatment to assess male sexual performance and induction of sterility. The method used to hold flies did not influence the aromatherapy effect. The mean time spent by wild females in copula with wild males was significantly longer than with sterile males for all treatments, except when sterile males were treated with $0.1 \mathrm{ml}$ of $\mathrm{GRO} / \mathrm{m}^{3}$. Amongst all doses studied, it is recommended to apply the lowest dose, $0.1 \mathrm{ml}$ of $\mathrm{GRO} / \mathrm{m}^{3}$, since at this dose both the RSI and induced sterility reached the highest levels, and were not statistically different from the 0.25 and $0.5 \mathrm{GRO} / \mathrm{m}^{3}$ doses. Indeed, this dose showed a very significant improvement in the mating competitiveness of sterile males aromatically treated with GRO.
\end{abstract}

\section{Introduction}

The low sexual performance of released sterile males is a serious challenge to improving the sterile insect technique (SIT) against the Mediterranean fruit fly, Ceratitis capitata (Wiedemann). Studies have focused on decreasing the negative effects of mass- production and irradiation (Fisher 1997; Fisher and Cáceres 2000; Calkins and Parker 2005; Parker 2005) and on understanding and enhancing the sexual performance of sterile males (Yuval et al. 1998; Hendrichs et al. 2002; McInnis et al. 2002; Shelly and Kennelly 2002). The exposure of sterile males of C. capitata to the aroma of ginger root oil 
(GRO), Zinziber officinalis Roscoe, before release is a simple procedure, feasible on a large scale (Shelly et al. 2004a; b) that might allow a lower over-flooding ratio in the field (Barry et al. 2003) whilst increasing the mating performance of sterile males up to three-fold (Shelly and McInnis 2001; McInnis et al. 2002; Shelly et al. 2002, 2003, 2007a; Paranhos et al. 2008). Aromatherapy using GRO does not affect the dispersion or survival of sterile males under field conditions (Shelly et al. 2004a, 2006; Paranhos et al. 2010).

However, few studies have been carried out to determine the optimal dose of GRO oil to treat sterile $C$. capitata males in programmes integrating the SIT. Amongst many GRO doses evaluated to treat sterile Mediterranean fruit fly males, Shelly et al. (2004a) have found that doses higher than $2 \mathrm{ml} /$ PARC fly holding box [volume of $0.075 \mathrm{~m}^{3}$ ( = ca. $\left.27 \mathrm{ml} / \mathrm{m}^{3}\right)$ ] had no significant effect on the relative mating success of $t s l$ males of the widely used genetic sexing strain VIENNA-7 (Franz 2005). It seems that overdoses do not provide any additional benefit for the sexual performance of sterile males. Besides, the routine use of a dose higher than necessary will be costly in SIT programmes in which hundreds of millions of sterile males are released per week.

As has been shown in the USA (Hawaii, California, and Florida), maturing sterile $C$. capitata males held in buckets, bags, towers, or boxes at fruit fly emergence and release facilities can be efficiently exposed to GRO on a mass scale using cotton wicks or panels in which the GRO aroma is dispersed in a closed room by ventilators (Shelly et al. 2007a). The amount of GRO used depends on the size of the room and the number of flies to be exposed. As little as $20 \mathrm{ml}$ of GRO has been successfully used to expose up to 10-12 million males overnight in large shipping trailers $\left(\sim 132 \mathrm{~m}^{3}\right)$ in the California sterile C. capitata preventive release programme (Shelly et al. 2007a).

Two methods are widely used for ground releases of sterile male Mediterranean fruit flies, roving fly releases using bags or 'chicken buckets' and point releases with larger containers, e.g. Plastic Adult Release Containers (PARC) boxes (FAO/IAEA 2007). The objective of this work was to evaluate four doses of GRO and two different methods (paper bags and plastic cages) to determine the minimum dose that produces an effective improvement in mating ability in sterile males when competing with wild males, and also induces the most egg sterility in wild females.

\section{Materials and methods}

\section{Location}

The experiments were carried out in the Entomology Laboratory of Embrapa Semiárido in Petrolina-PE, northeastern Brazil. The environmental conditions were $25-27^{\circ} \mathrm{C}, 50-60 \% \mathrm{RH}$, and a photoperiod of 12:12 (L:D).

\section{Insects}

Wild C. capitata flies were derived from larvalinfested guava fruits collected in the San Francisco River Valley of northeastern Brazil. Larvae completed development in situ, and pupae were sifted from vermiculite placed beneath the fruits. One day after emergence, ca. 500 flies were separated for each sex (FAO/IAEA/USDA 2003) and maintained inside screened cages $(30 \times 30 \times 30 \mathrm{~cm})$ in a room under natural conditions, i.e. temperature ranging between 27 and $31{ }^{\circ} \mathrm{C}$ and relative humidity between 10 and $80 \%$. Wild flies had free access to water and food [ 1 part hydrolysed yeast protein, 3 parts sugar, plus $10 \%$ wheat germ (by wgt)] until sexually mature (8-10 days old).

The sterile males, which were provided by the Biofabrica Moscamed Brasil, Juazeiro, Brazil, were from the $t$ s-VIENNA-8 strain and were irradiated as pupae 2 days before emergence with a dose of $95 \mathrm{~Gy}$ of gamma irradiation from a ${ }^{60} \mathrm{Co}$ source (Gammacell 220 Excel; MDS Nordion, Ottawa, ON). Half of the sterile males were kept in ventilated plastic cages $(21 \times 13 \mathrm{~cm})$ and the other half in paper bags $(35 \mathrm{~g} /$ $\mathrm{m}^{2}$, porosity of $15 \mathrm{seg} / 100 \mathrm{ml}, 20 \times 43 \mathrm{~cm}$ ) at $30 \mathrm{ml}$ (ca. 1800 pupae) of irradiated pupae. Like the PARC boxes, the plastic cages used in these experiments had a screened opening $(12 \times 8 \mathrm{~cm})$ on the cover allowing for ventilation and feeding. After emergence, the sterile males were kept under laboratory conditions, with free access to a jelly prepared with agar $(10 \mathrm{~g})$, water $(700 \mathrm{ml})$ and bee honey $(300 \mathrm{ml})$, until the flies reached sexual maturity (4-5 days old). To keep the males alive, the paper bags were sprayed with water three to four times a day, and the plastic cages were provided with water in moist cotton. For aromatherapy, the 4- to 5-day old sterile males were exposed to $0,0.1,0.25,0.5$ or $0.75 \mathrm{ml}$ of ginger root oil $(\mathrm{GRO}) / \mathrm{m}^{3}$ applied on a piece of toilet paper placed on the bottom of an opened Petri dish, using a microcapillary pipette. The aroma was dispersed by one air fan in each room (low velocity$180 \mathrm{rpm}, 50-60 \mathrm{~Hz}$ ), for $20 \mathrm{~h}$, under the same lab 
conditions described above. The GRO was obtained from Citrus and Allied Essences ${ }^{\circledR}$, Lake Success, NY, with $92 \%$ purity and $0.4 \%$ of $\alpha$-copaene $(\mathrm{C} 15 \mathrm{H} 24)$. The wild insects (no GRO), control sterile males (no GRO), and sterile males exposed to each of the different doses of GRO, were each kept in separate $\left(\sim 25 \mathrm{~m}^{3}\right)$ rooms.

\section{Experiments}

The day before the start of a mating test, wild males (8-15 days old) or sterile males (5-7 days old), alternately, were marked on the thorax with a white dot of water soluble atoxic ink (Faber-Castell@, São Paulo, Brazil). Males were put inside screen bags, 10 at a time, and gently immobilized between two fingers, one by one, to facilitate the marking procedure (FAO/IAEA/USDA 2003).

The mating tests were carried out under laboratory conditions, in Plexiglas cages $(20 \times 20 \times 20 \mathrm{~cm})$, with free access to water and honey jelly, as described above. The number of cages or replicates per treatment set up on each of the experimental days was dependent on the number of wild flies available.

Ten wild and ten sterile males were released per cage at 7:30, and 10 min later, when the males were pheromone calling, ten wild females were released inside the mating cages. All treatments had the same number of sterile males, wild males, and wild females (10:10:10), and both types of males were in competition to mate with the wild females. Mating pairs were collected individually and kept in acrylic vials $(20 \mathrm{ml})$ until the pairs uncoupled. The pairs were collected from 7:45 until 12:30.

Soon after uncoupling, all mated females, separately by treatment, were released inside Plexiglas cages described above, with full access to water, food, and grape berries for oviposition. The berries were replaced every $24 \mathrm{~h}$ and dissected to collect the eggs. The number of eggs collected in each cage was dependent on the number of mated females in the cages, varying from 30-170 eggs/day. Eggs were collected on successive days with the goal of obtaining 500 per treatment, and were placed on moist blotter paper in a Petri dish at $25^{\circ} \mathrm{C}$, then scored for hatch 4 days later.

We recorded number of matings, copula duration, and egg hatch for sterile and wild males. Sterile male performance was assessed based on the Relative Sterility Index (RSI) for each dose (FAO/IAEA/USDA 2003), as well as by the competitiveness value of sterile males based on RSI, C(RSI). The RSI is defined as follows:

$$
\mathrm{RSI}=\frac{\mathrm{SW}}{\mathrm{SW}+\mathrm{WW}},
$$

where SW is the number of sterile copulation and WW is the number of wild copulation. The $\mathrm{C}(\mathrm{RSI})$ is defined as follows:

$$
\mathrm{C}(\mathrm{RSI})=\frac{\mathrm{RSI}}{1-\mathrm{RSI}},
$$

which compares the proportion of sterile male matings to the proportion of wild male matings. Since the numbers of sterile and wild males for each test is the same (10), the expected RSI $=0.5$ and the $\mathrm{C}(\mathrm{RSI})=1.0$ if sterile male competitiveness equals that of wild males.

\section{Data analysis}

The experimental design was a completely randomized factorial with four doses (plus a control) and two methods of holding the flies with different repetitions. The number of repetitions was different for each GRO treatment and for the two types of methods. In the control $\left(0 \mathrm{ml}\right.$ of $\left.\mathrm{GRO} / \mathrm{m}^{3}\right)$, we had 19 repetitions for paper bags and 17 for plastic cages. For $0.1-0.5 \mathrm{ml}$ of $\mathrm{GRO} / \mathrm{m}^{3}$, we had 11 repetitions for paper bags and 10 for plastic cages, and for $0.75 \mathrm{ml}$ of $\mathrm{GRO} / \mathrm{m}^{3}$ we had 14 repetitions for both paper bags and plastic cages (Calado and Montgomery 2003). Normality and variance homogeneity assumptions were previously tested using Smirnof-Kolmogorov and Levene tests, respectively (Hill and Lewicki 2006).

A completely randomized design was used. An analysis of variance (ANOVA) was applied to treatments (GRO doses and method) and variables (RSI, egg hatch, and copula duration). The Anova analysis was performed using sPSS 2006 V. 15 GLM procedure, a method unique with SST calculation Type III, as described in Maroco (2007). Mean comparisons were analysed by Tukey's honestly significant difference (HSD) test at $\mathrm{P}=0.05$. The factor 'method' was never significant based on the ANOVA statistics, so the number of repetitions used in the Tukey's test was the combined number of mating cages with flies from paper bags and plastic cages.

For sterile male copula duration, the numbers of couples observed and analysed were 35, 20, 21, 20 and 28 for the treatments $0,0.1,0.25,0.5$ and $0.75 \mathrm{ml}$ of $\mathrm{GRO} / \mathrm{m}^{3}$, respectively. The corresponding numbers of mating couples for non-treated wild 
males were $36,19,21,17$ and 28 , respectively. An arcsine square root transformation was applied to the percentage data to normalize their distribution. The data for copula duration from sterile and wild fly couples were compared using a Student's T-test (Sokal and Rohlf 1995).

\section{Results}

There was no difference between the two types of fly holding methods (paper bags and plastic cages) for all variables studied, such as RSI $\left(\mathrm{F}_{1,126}=0.001\right.$; $\mathrm{P}=0.854)$, egg hatch $\left(\mathrm{F}_{1,126}=0.089 ; \mathrm{P}=0.894\right)$, sterile male copula duration $\left(\mathrm{F}_{1}, \quad 124<0.001\right.$; $\mathrm{P}=0.990)$ and wild male copula duration $\left(\mathrm{F}_{1}\right.$, $\left.{ }_{121}=0.861 ; \mathrm{P}=0.471\right)$. The interaction term (doses $\times$ method) was not significant for any of the variables observed. Therefore, the statistically homogeneous data for paper bags and plastic cages were thereafter combined for each dose.

There was a statistical difference in the RSI obtained for sterile males aromatically treated with different doses of GRO $\left(\mathrm{F}_{4,126}=7.820 ; \mathrm{P}<0.001\right)$. The RSIs from sterile males treated with 0.1 and $0.5 \mathrm{ml} \mathrm{GRO} / \mathrm{m}^{3}$ were significantly higher than the RSI for the control dose 0 (not exposed to GRO); whilst the RSIs for sterile males treated with 0.25 and $0.75 \mathrm{ml} \mathrm{GRO} / \mathrm{m}^{3}$ were not significantly different from the RSIs obtained for sterile males not exposed to GRO (fig. 1). Untreated males and $0.75 \mathrm{ml}$ GRO/ $\mathrm{m}^{3}$ treated males both had average RSIs lower than 0.5 indicating that those sterile males were less competitive than wild males. The highest RSI value (0.67) was obtained for the lowest GRO dose $\left(0.1 \mathrm{ml} / \mathrm{m}^{3}\right)$.

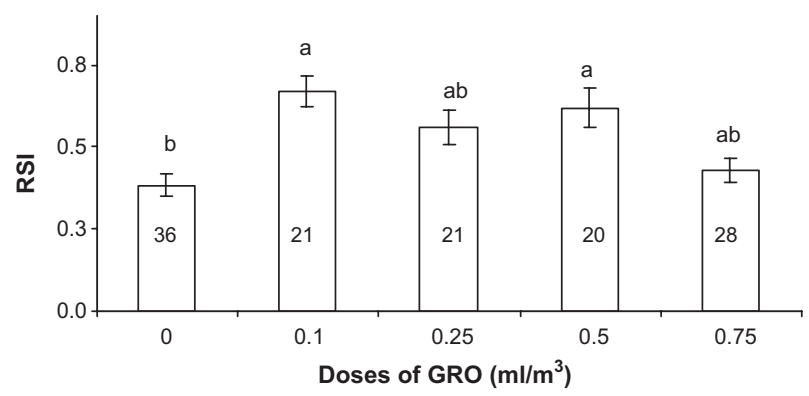

Fig. 1 The Relative Sterility Index (RSI) for sterile males of Ceratitis capitata exposed to different doses of ginger root oil (GRO) in competition with wild males for mating with wild females (where $0 \mathrm{ml}$ represents control males not exposed to GRO). Inside columns are the numbers of repetitions combined over both types of fly holding methods. Columns with the same letter do not differ significantly (Tukey's test, $\mathrm{P}>0.05)$. Vertical bars represent the standard errors.
Table 1 Mating competitiveness values of sterile males of Ceratitis capitata in relation to wild males, C(RSI), exposed or non-exposed to ginger root oil (GRO) at various doses $(0.0,0.1,0.25,0.50$ and $0.75 \mathrm{ml} / \mathrm{m}^{3}$ ), along with the degree of improvement from GRO treatment at each dose, expressed as a ratio to control males (dose $=0.0$ ). Data were combined for both methods (paper bags and plastic cages)

\begin{tabular}{lll}
\hline GRO dose & $\mathrm{C}(\mathrm{RSI})$ value (avg.) & Ratio [C(RSI) treatment/ \\
$\left(\mathrm{ml} / \mathrm{m}^{3}\right)$ & $(\mathrm{RSI}) /(1-\mathrm{RSI})$ & $\mathrm{C}(\mathrm{RSI})$ control]
\end{tabular}

\begin{tabular}{lll}
\hline 0.00 & 0.61 & 1.00 \\
0.10 & 2.03 & 3.33 \\
0.25 & 1.25 & 2.08 \\
0.50 & 1.63 & 2.64 \\
0.75 & 0.75 & 1.23 \\
\hline
\end{tabular}

The competitiveness values for control and treated sterile males are shown in table 1. For unexposed males, a C(RSI) value of 0.61 was obtained [RSI/( 1 RSI $)=(0.38 / 0.62)=0.61]$. For the dose of $0.1 \mathrm{ml} /$ $\mathrm{m}^{3}$, the $\mathrm{C}(\mathrm{RSI})$ was 2.03 , meaning that the treated males at that dose had ca. twice the competitiveness of wild males and ca. 3.3 times the competitiveness of control, unexposed males.

There was a statistical difference in egg hatch amongst treatments $\left(\mathrm{F}_{4}, 126=3\right.$. 631; $\left.\mathrm{P}=0.009\right)$. The egg hatch was significantly higher when sterile males were not aromatically treated with GRO (control) and when they were treated with the highest GRO dose $\left(0.75 \mathrm{ml}\right.$ of $\left.\mathrm{GRO} / \mathrm{m}^{3}\right)$ compared to the doses of 0.1 and $0.5 \mathrm{ml}$ of $\mathrm{GRO} / \mathrm{m}^{3}$ (fig. 2). The lowest values for egg hatch (the highest sterility) coincided with the highest mating competitiveness (RSI), whilst the highest egg hatch values (lowest sterility) coincided with the lowest mating competitiveness (RSI). Higher GRO concentration did not confer

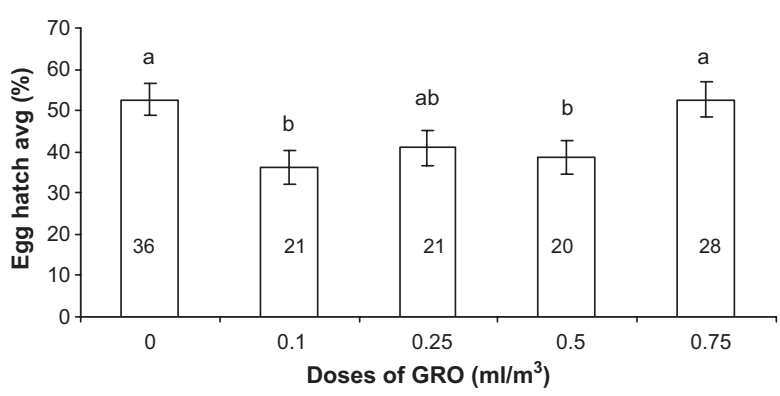

Fig. 2 Percentage egg hatch after 10 sterile males of Ceratitis capitata exposed to different doses of ginger root oil (GRO) competed with 10 wild males for 10 wild females, in laboratory cages. Inside columns are the numbers of repetitions combined over both types of methods. Columns with the same letter do not differ significantly (Duncan's test, $P>0.05)$. Vertical bars represent the standard errors. 


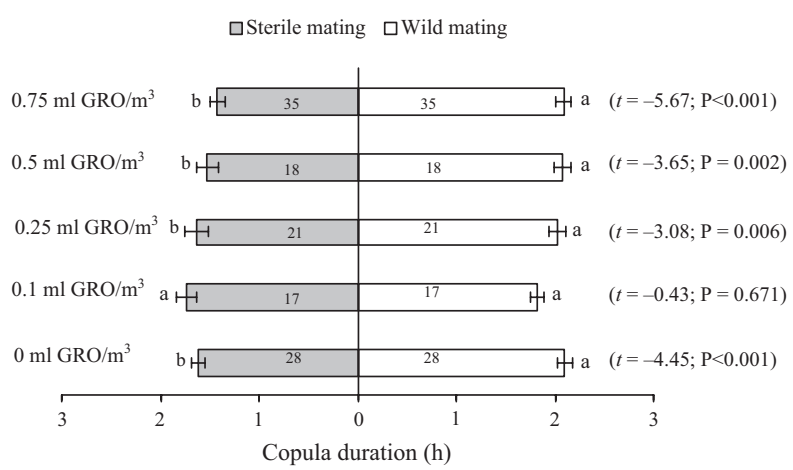

Fig. 3 Average copula duration (hours) of wild females Ceratitis capitata with sterile males (grey bars) exposed to different doses of ginger root oil (GRO) and with wild males (white bars). Inside columns are the numbers of repetitions. Columns for the same treatment with the same letter do not differ significantly by Student's t-test. Horizontal bars represent the standard errors.

benefits to treated males. In doses above $0.10 \mathrm{ml}$ of $\mathrm{GRO} / \mathrm{m}^{3}$ there was no added effect, neither in the RSI (fig. 1) nor in egg sterility (fig. 2).

There was no statistically significant difference in copula duration for sterile males amongst different GRO doses $\left(\mathrm{F}_{4,124}=1.942 ; \mathrm{P}=0.108\right)$ nor in copula duration for wild mating males collected in the different treatments $\left(\mathrm{F}_{4,121}=1.524 ; \mathrm{P}=0.200\right)$. However, a Student's $t$-test was performed to compare copula duration from sterile males exposed to 0; $0.25 ; 0.5$ and $0.75 \mathrm{ml}$ of $\mathrm{GRO} / \mathrm{m}^{3}$ and wild males which were in competition with sterile males to mate with wild females in each treatment. The results showed a significant difference $(\mathrm{P}<0.05)$ between sterile and wild copula duration for treatments $0 ; 0.25 ; 0.5$ and $0.75 \mathrm{ml}$ of $\mathrm{GRO} / \mathrm{m}^{3}$ (fig. 3). Thus, wild male copula durations were longer than sterile male copulations for all treatments except when the sterile males were treated with $0.1 \mathrm{ml}$ of GRO $/ \mathrm{m}^{3}$ (fig. 3).

\section{Discussion}

Aromatherapy with GRO can be used successfully for Mediterranean fruit fly males emerged and kept in paper bags or in plastic cages. The $\alpha$-copaene attractant present in GRO (Shelly 2001) apparently enters equally into the paper bags and the plastic containers to treat sterile males. However, paper bags are not recommended in fly holding places with low humidity, because flies are not easily provided with water leading to high mortality before reaching the age of release and sexual maturity, as recommended by McInnis et al. (2013).
Aromatherapy improved the RSI in laboratory mating competitiveness experiments, and increased the sexual success of sterile males to mate and transfer sperm, instead the females fertility decreased. The mating competitiveness of sterile males, C(RSI), at a dose of $0.1 \mathrm{ml} / \mathrm{m}^{3}$ was more than three times that of untreated sterile males and twice that of wild males. However, for doses higher than $0.1 \mathrm{ml}$ of $\mathrm{GRO} / \mathrm{m}^{3}$, there was no additional beneficial effect in sexual performance (RSI) or in egg sterility. In fact, males treated with the highest GRO dose $(0.75 \mathrm{ml}$ of $\mathrm{GRO} / \mathrm{m}^{3}$ ) showed a non-significantly lower sexual competitiveness compared to the lowest dose $(0.1 \mathrm{ml}$ of $\mathrm{GRO} / \mathrm{m}^{3}$ ), with RSI values of 0.43 and 0.67 , respectively. Thus, we observed that the lowest tested concentration of GRO could be optimally and successfully used for $C$. capitata aromatherapy in operational SIT programmes. Also, Morelli et al. (2013) working with the same dose $(0.1 \mathrm{ml}$ of GRO/ $\mathrm{m}^{3}$ ) found that male exposure to GRO aroma resulted in a reduction of female receptivity after mating, comparable to matings with wild males. This mating reduction was, in turn, greater than that found for females mated with sterile non-exposed males, and this was evident for both the remating rate and the mean number of matings achieved per female. Nevertheless, the experiments performed were conducted in small laboratory cages so the data should be confirmed in standard field cage tests according to the standard quality control manual (FAO/IAEA/USDA 2003). After many studies showing the improvement of $C$. capitata sterile male sexual performance after treatment with GRO, Shelly and coworkers (2007a) also did not find any additional benefit above the significant mating advantage already shown for all doses when ca. 10-12 million sterile males kept in PARC boxes in trailers $\left(132 \mathrm{~m}^{3}\right)$ were treated with increasing amounts of GRO-18, 36 and $45 \mathrm{ml}$, i.e. $0.13,0.27$ and $0.34 \mathrm{ml} / \mathrm{m}^{3}$.

It is known that exposing males to GRO does not enhance male pheromone attractiveness (Papadopoulos et al. 2006) nor produce consistent differences in male courtship behaviour of sterile males (Briceño et al. 2007), nor does it confer direct reproductive benefits to females (Shelly 2005). Also, at the age sterile males are treated with GRO (ca. 4 days old), the testis are completely developed with free sperm in the seminal vesicle (Anwar et al. 1971), and the accessory glands contain a large amount of fluid (Marchini et al. 2003). The fact that GRO aromatherapy apparently alters the male's cuticular odour perceptible to females at short distances (Papadopoulos et al. 2006; Briceño et al. 2007; Shelly et al. 2007b) 
may account for the enhanced mating success of GRO-exposed sterile males.

Wild matings are usually longer than sterile ones, and can be a consequence of sterilization, since Paranhos et al. (2008) have found longer mating duration for fertile Vienna 8-tsl males than for sterile ones. Indeed, when fertile males were treated with GRO they had similar mating durations as wild males, but the same did not happen for sterile males treated with GRO. In this study we have found that sterile males untreated or treated with GRO had shorter mating durations than wild males, as found in previous studies (Shelly et al. 2003; Paranhos et al. 2008; Morelli et al. 2013); however, when sterile males were exposed to $0.1 \mathrm{ml}$ of $\mathrm{GRO} / \mathrm{m}^{3}$ their mating duration was similar to wild males. Amongst the GRO doses we have studied, $0.1 \mathrm{ml}$ of $\mathrm{GRO} / \mathrm{m}^{3}$ was the only dose to increase the mating duration of sterile males of the Vienna $8 \mathrm{tsl}$ strain, as above this dose there was no effect on the mating duration.

There is no supportive study indicating how many minutes would be necessary for medflies to transfer a complete quantity of semen and accessory gland fluid to avoid or decrease the possibility of remating. Nevertheless, according to Seo et al. (1990) and Taylor et al. (2001), medfly males from mass rearing and after sterilization transfer less sperm than wild males, and the amount of seminal fluid transferred is not correlated with time mating. In other words, there is no linear increase between sperm storage and mating duration (Farias et al. 1972; Anne Moreira Costa, unpublished data).

From an applied point of view, SIT implementation is more successful when using sterile males treated with GRO as lower numbers of sterile males would be required to get the same level of egg sterility in wild populations compared with untreated males (Barry et al. 2003). It is known that aromatherapy with GRO does not negatively affect the dispersion and survival of sterile Mediterranean fruit fly males (Shelly et al. 2004b, 2006; Paranhos et al. 2010). So GRO can be used without risk in terms of survival or flight activity to aromatically treat sterile $C$. capitata males before their release, to improve their sexual performance in the field. Amongst doses that increased sexual performance of sterile $t s$ VIENNA- 8 males and the sterility they induced, it is recommended to use the lowest dose, $0.1 \mathrm{ml}$ of $\mathrm{GRO} / \mathrm{m}^{3}$, because it was not statistically different from doses of 0.25 and $0.5 \mathrm{ml}$ of $\mathrm{GRO} / \mathrm{m}^{3}$, and showed the most effective improvement in the mating competitiveness of sterile males aromatically treated with GRO. Despite an already very low cost on a mass scale, US \$1,00/million sterile flies, even lower doses could be tested.

\section{Acknowledgements}

We would like to thank Todd Shelly for comments on an earlier version of the manuscript and also Biofábrica Moscamed Brasil for providing the sterile males for these experiments. This research was supported by the Food and Agriculture Organization/ International Atomic Energy Agency (FAO/IAEA) through research contract No 13495.

\section{References}

Anwar M, Chambers DL, Ohinata K, Kobayashi RM, 1971. Radiation-sterilization of the Mediterranean fruit fly (Diptera:Tephritidae): comparison of spermatogenesis in flies treated as pupae or adults. Ann. Entomol. Soc. Am. 64, 627-633.

Barry JD, Shelly TE, McInnis DO, Morse J, 2003. Potential for reducing overflooding ratios of sterile Mediterranean fruit flies (Diptera: Tephritidae) with the use of ginger root oil. Fla. Entomol. 86, 29-33.

Briceño D, Eberhard W, Shelly T, 2007. Male courtship behaviour in Ceratitis capitata (Diptera: Tephritidae) that have received aromatherapy with ginger root oil. Fla. Entomol. 90, 175-179.

Calado V, Montgomery DC, 2003. Planejamento de experimentos utilizando o Statistica. E-paper Serviços Editoriais, Rio de Janeiro, 260p.

Calkins CO, Parker AG, 2005. Sterile insect quality. In: Sterile insect technique: principles and practice in area-wide integrated pest management. Ed. by Dyck VA, Hendrichs J, Robinson AS, Springer, Netherlands, 269-296.

FAO/IAEA, 2007. Guidance for packing, shipping, holding and release of sterile flies in area-wide fruit fly control programmes. FAO Plant Production and Protection Paper, 190, Rome, Italy. pp. 1-134.

FAO/IAEA/USDA, 2003. Manual for product quality control and shipping procedures for sterile- mass-reared tephritid fruit flies, 5th edn. International Atomic Energy Agency, Vienna, 85p.

Farias GT, Cunningham RT, Nakagawa S, 1972. Reproduction in the Mediterranean fruit fly: abundance of stored sperm affected by duration of copulation and affecting egg hatch. J. Econ. Entomol. 65, 914-915.

Fisher K, 1997. Irradiation effects in air and in nitrogen on Mediterranean fruit fly (Diptera: Tephritidae) pupae in Western Australia. J. Econ. Entomol. 90, 1609-1614. 
Fisher K, Cáceres C, 2005. A filter rearing system for mass reared medfly. In: Sterile insect technique: principles and practice in area-wide integrated pest management. Ed. by Dyck VA, Hendrichs J, Robinson AS, Springer, the Netherlands, 543-550.

Fisher K, Cáceres C, 2000. A filter rearing system for mass reared genetic sexing strains of Mediterranean fruit fly (Diptera: Tephritidae). pp. 543-550 In: AreaWide Control of Fruit Flies and Other Insect Pests. Ed. by K. H. Tan, Penerbit Universiti Sains Malaysia, Penang, Malaysia. 782 pp.

Franz G, 2005. Genetic sexing strains. In: Mediterranean fruit fly, an example for other species amenable to large-scale rearing for the Sterile Insect Technique. Ed. by Dyck VA, Hendrichs J, Robinson AS, Springer, the Netherlands, 427-451.

Hendrichs J, Robinson AS, Cayol JP, Enkerlin W, 2002. Medfly areawide Sterile Insect Technique programmes for prevention, suppression or eradication: the importance of mating behavior studies. Fla. Entomol. 85, $1-13$.

Hill T, Lewicki P, 2006. Statistics - Methods and applications. Statsoft Inc., Tulsa, OK, USA.

Marchini D, Del Bene G, Cappelli L, Dallai R, 2003. Ultrastructure of the male reproductive accessory glands in the medfly Ceratitis capitata (Diptera: Tephritidae) and preliminary characterization of their secretions. Arthropod Struc. Dev. 31, 313-327.

Maroco J, 2007. Análise Estatística utilizando o SPSS, 3rd edn. Edições Sílabo, Lisboa.

McInnis DO, Shelly TE, Komatsu J, 2002. Improving male mating competitiveness and survival in the field for medfly, Ceratitis capitata (Diptera: Tephritidae) SIT programs. Genetica 116, 117-124.

McInnis DO, Paranhos BJ, Shelly TE, 2013. Survival of sterile male Mediterranean fruit flies in large field cages after release at different ages. J. Appl. Entomol. 137(Suppl. 1), 43-48.

Morelli R, Paranhos BJ, Coelho AM, Castro R, Garziera L, Lopes F, Bento JMS, 2013. Exposure of sterile Mediterranean fruit fly (Diptera: Tephritidae) males to ginger root oil reduces female remating. J. Appl. Entomol. 137(Suppl. 1), 75-82.

Papadopoulos NT, Shelly TE, Niyazi N, Jang E, 2006. Olfactory and behavioural mechanisms underlying enhanced mating competitiveness following exposure to ginger root oil and orange oil in males of the Mediterranean fruit fly, Ceratitis capitata (Diptera: Tephritidae). J. Insect Behav. 19, 403-418.

Paranhos BJ, McInnis DO, Uramoto K, Damasceno I, Gonçalves N, Alves RM, Costa MLZ, Walder JMM, Malavasi A, Nascimento A, 2008. Sterile medfly males of the tsl Vienna 8 genetic sexing strain improved mating performance with ginger root oil. In: Fruit flies of economic importance: from basic to applied knowl- edge. Ed. by Sugayama RL, Zuchi RA, Ovruski SM, Sivinski J, SBPC, Salvador, 313-318.

Paranhos BJ, Papadopoulos N, McInnis D, Gava C, Lopes FSC, Morelli R, Malavasi A, 2010. Field dispersal and survival of sterile medfly males aromatically treated with ginger root oil. Environ. Entomol. 39, 570-579.

Parker AG, 2005. Mass-rearing for sterile insect release. In: Sterile insect technique: principles and practice in area-wide integrated pest management. Ed. by Dyck VA, Hendrichs J, Robinson AS, Springer, the Netherlands, 209-232.

Seo ST, Vargas RI, Gilmore JE, Kurashima RS, Fugimoto MS, 1990. Sperm transfer in normal and gammairradited, laboratory-reared mediterranean fruit flies (Diptera: Tephritidae). J. Econ. Entomol. 83, 1949-1953.

Shelly TE, 2001. Exposure to alpha-copaene and alphacopaene-containing oils enhances mating success of male Mediterranean fruit flies (Diptera: Tephritidae). Ann. Entomol. Soc. Am. 94, 497-502.

Shelly TE, 2005. Does mating with ginger root oil-exposed males confer fitness benefits to female Mediterranean fruit flies, Ceratitis capitata (Diptera: Tephritidae)? Proc. Hawaiian Entomol. Soc. 37, 65-71.

Shelly TE, Kennelly S, 2002. Influence of male diet on male mating success and longevity and female remating in the Mediterranean fruit fly (Diptera: Tephritidae) under laboratory conditions. Fla. Entomol. 85, 572-578.

Shelly TE, McInnis DO, 2001. Exposure to ginger root oil enhances mating success of irradiated, mass-reared males of Mediterranean fruit fly (Diptera: Tephritidae). J. Econ. Entomol. 94, 1413-1418.

Shelly TE, Robinson AS, Cáceres C, Wornoayporn V, Islan A, 2002. Exposure to ginger root oil enhances mating success of male Mediterranean fruit flies (Diptera: Tephritidae) from a genetic sexing strain. Fla. Entomol. 84, 440-445.

Shelly TE, Rendon E, Hernadez E, Salgado S, McInnis DO, Villalobos E, Liedo P, 2003. Effects of diet, ginger root oil, and elevation on the mating competitiveness of male Mediterranean fruit flies (Diptera: Tephritidae) from a mass-reared, genetic sexing strain in Guatemala. J. Econ. Entomol. 96, 1132-1141.

Shelly TE, McInnis DO, Pahio E, Edu J, 2004a. Aromatherapy in the Mediterranean fruit fly (Diptera: Tephritidae): sterile males exposed to ginger root oil in pre-releases, storages boxes display increase mating competitiveness in field-cage trials. J. Econ. Entomol. 97, 470-481.

Shelly TE, Edu J, Pahio E, 2004b. Sterile males of the Mediterranean fruit fly exposed to ginger root oil induce female remating: implications for the sterile insect technique (Diptera: Tephritidae). Fla. Entomol. $87,628-629$. 
Shelly TE, Holler TC, Stewart JL, 2006. Mating competitiveness of mass-reared of the Mediterranean fruit fly (Diptera: Tephritidae) from eclosion towers. Fla. Entomol. 89, 380-387.

Shelly T, Edu J, Smith E, Hoffman K, War M, Santos R, Favela A, Garagliano R, Ibewiro B, McInnis D, 2007a. Aromaterapy on a large scale: exposing entire holding rooms to ginger root oil increases the mating competitiveness of sterile males of Mediterranean fruit fly. Entomol. Exp. Appl. 123, 193-201.

Shelly TE, Edu J, Pahio E, Nishimoto J, 2007b. Scent males and choosy females: does male odor influence female mate choice in the Mediterranean fruit fly? J. Chem. Ecol. 33, 2308-2324.

Sokal RR, Rohlf FJ, 1995. Biometry: the principles and practice of statistics in biological research, 3rd edn. W.H. Freeman, New York.

Taylor PW, Kaspi R, Mossison S, Yuval B, 2001. Agedependent insemination success of sterile Mediterranean fruit flies. Entomol. Exp. Appl. 98, 27-33.

Yuval B, Kaspi R, Sholmit S, Warburg MS, 1998. Nutritional reserves regulate male participation in Mediterranean fruit fly leks. Ecol. Entomol. 23, 211-215.

This article was published online on 16 December 2010. The references for McInnis et al. (2013) and Morelli et al. (2013) have now been updated to show the correct citation details for J. Appl. Entomol. Vol. 137, Suppl. 1. 